Cite this: Phys. Chem. Chem. Phys., 2012, 14, 10523-10532

\title{
Tailoring the morphology of Pd nanoparticles on CNTs by nitrogen and oxygen functionalization $\dagger$
}

\author{
Rosa Arrigo, ${ }^{* a}$ Sabine Wrabetz, ${ }^{a}$ Manfred E. Schuster, ${ }^{a}$ Di Wang, ${ }^{a b}$ Alberto Villa, ${ }^{c}$ \\ Dirk Rosenthal, ${ }^{a}$ Frank Girsgdies, ${ }^{a}$ Gisela Weinberg, ${ }^{a}$ Laura Prati, ${ }^{c}$ \\ Robert Schlögl ${ }^{a}$ and Dang Sheng Su*a
}

Received 11th February 2012, Accepted 28th May 2012

DOI: $10.1039 / \mathrm{c} 2 \mathrm{cp} 40861 \mathrm{a}$

The influence of $\mathrm{N}$ and $\mathrm{O}$ functionalization of CNT on the morphology of supported Pd-PVA nanoparticles is studied with respect to the catalytic activity in the liquid phase oxidation of benzyl alcohol to benzaldehyde. The impact of specific $\mathrm{N}$ and $\mathrm{O}$ sites on the carbon surface induced by the high temperature $\mathrm{N}$-functionalization in the temperature range $673-873 \mathrm{~K}$ was observed by HRTEM as increased nanoparticles dispersion and enhanced metal wetting at the carbon surface. Those small nanoparticles that stabilized at the N-CNTs surface are beneficial for improving catalytic performance. The interaction of $\mathrm{O}_{2}$ with the metal surface was studied by microcalorimetry. At $353 \mathrm{~K}$, the PVA shell hinders the dissociative oxygen chemisorption at the surface of the fresh catalyst. Differently, a very high (maximum for Pd/N-CNT873K $750 \mathrm{~kJ} \mathrm{~mol}^{-1}$ ) and oscillating exothermic differential heat is registered for the washed samples. Such high differential heat on the "washed" sample is due to the sum of oxygen chemisorption and PVA oxidation. Thereby, it is demonstrated that the PVA overlayer suppresses the total combustion reaction pathway. This contribution has highlighted the impact of the dynamic change of morphology of these Pd nanoparticles under the reaction conditions on the catalytic performance and how this is modulated by the nature of the support as well as the PVA. The support with its varying ability to strongly bind Pd regulates the morphology of the nanoparticles on which the sub-surface penetration of $\mathrm{O}, \mathrm{H}, \mathrm{C}$ from the reactants depends, all modulating the electronic structure and thus the reactivity.

\section{Introduction}

The development of solid catalysts for selective oxidation of alcohols to valuable oxygenated compounds for the production of fine and specialty chemicals is a subject of growing interest. ${ }^{1-5}$ In this field of research, the sol-immobilization of stabilized noble metal nanoparticles from a colloidal solution onto a support surface is a well-established preparation route to obtain active catalysts. ${ }^{6-9}$ Several catalytic systems based on noble metal nanoparticles have been investigated for the

\footnotetext{
${ }^{a}$ Dept. Anorganische Chemie Fritz-Haber-Institut der Max-Planck Gesellschaft, Faradayweg 4-6, 14195 Berlin, Germany. E-mail: arrigo@fhi-berlin.mpg.de,dangsheng@fhi-berlin.mpg.de; Fax: $+49 / 30 / 8413-4685,+49 / 30 / 8413 / 4401$;

Tel: $+49 / 30 / 8413-4648,+49 / 30 / 8413 / 4633$

${ }^{b}$ Karlsruhe Institut für Technologie, Hermann-von-Helmholtz-Platz 1, 76344 Eggenstein-Leopoldshafen, Germany

${ }^{c}$ Department of Inorganic Chemistry L. Malatesta, Università degli Studi di Milano via Venezian 21, 20133 Milano, Italy

${ }^{d}$ Shenyang National Laboratory for Materials Science, Institute of Metal Research, Chinese Academy of Sciences, 72 Wenhua Road, 110016 Shenyang, China

$\dagger$ Electronic supplementary information (ESI) available. See DOI: $10.1039 / \mathrm{c} 2 \mathrm{cp} 40861 \mathrm{a}$
}

oxidation of alcohol with molecular oxygen or hydrogen peroxide. Research has focused on the use of $\mathrm{Pt} / \mathrm{C}$ or $\mathrm{Pd} / \mathrm{C}$ catalysts. ${ }^{3,10}$ In the studies reported in the literature, the target in the catalyst synthesis is the achievement of a narrow size distribution of metal nanoparticles, approaching the ideal mono-dispersion. The size of the nanoparticles is considered as one of the directly controllable parameters related to structural features that determines the reactivity and the selectivity of the catalyst. ${ }^{11}$ The sol-immobilization strategy is in particular attractive because the particle size distribution can be tuned by the nature and concentration of the protective agent and the reductive agent. ${ }^{7,8,12}$

Commercial carbon supports have often been used for the macroscopic assembling of the metal nanoparticles; however the influence of the surface chemistry of the carbon support on the adsorption of the metal nanoparticles and the wetting of the metal at the carbon surface was not clarified. In order to obtain noble metal nanoparticles homogeneously dispersed on the carbon surface, it is important to maximize the particlesupport interaction during the adhesion process of the polyvinyl alcohol (PVA)-protected nanoparticles on the carbon surface against the particle-particle interaction. A recent report ${ }^{13}$ 
has highlighted the beneficial effect of nitrogen containing organic moieties grafted onto the surface of CNTs for obtaining homogeneously dispersed gold nanoparticles. We have also reported about the beneficial effect of $\mathrm{N}$-functionalization of the CNT surface for improving the catalytic performance of the Pd nanoparticles-based catalyst obtained via a sol immobilization method in the liquid phase selective oxidation of benzyl alcohol to benzaldehyde ${ }^{14}$ and in the liquid phase direct synthesis of hydrogen peroxide from $\mathrm{H}_{2}$ and $\mathrm{O}_{2}{ }^{15}$ The nature of the interaction at the metal/support interface also influences the catalytic reactivity of the metal nanoparticles-based catalyst. $^{16-19}$ Thus, it is important to elucidate the role that the surface chemistry of the support plays in the preparation of immobilized metal nanoparticles. ${ }^{16,17}$

Theoretical studies on the system Pt on nanocarbon (NC) have highlighted the fundamental effect of the metal-support interaction and the morphology of the NC surface on the morphology of the metal nanoparticles and thus on the coordination number of the metal atoms at the particles surface, which determine the catalyst reactivity. ${ }^{20}$

This work aims to gain insight into the role that the surface chemistry of the carbons plays in the metal/carbon interfacial interaction and thus in the metal nanostructure studied by HRTEM. We also study how the reactivity of the metal nanoparticles in the liquid phase oxidation is influenced by the Pd nanostructure. CNTs containing nitrogen and oxygen functionalities with different surface chemical properties (acid/base and hydrophobic/hydrophilic) are used as support for Pd nanoparticles and applied in the liquid phase oxidation of benzyl alcohol to benzaldehyde by molecular oxygen under solventless conditions.

The interaction of oxygen with the surface of $\mathrm{Pd}$ nanoparticles-based catalysts is studied by reactive microcalorimetry at the reaction temperature used for the liquid phase oxidation of benzyl alcohol to benzaldehyde. The $\mathrm{H}_{2}$ and $\mathrm{CO}$ chemisorption was carried out on two differently performing catalysts to investigate the specific surface area.

\section{Materials and methods}

\subsection{CNTs functionalization}

Commercial carbon nanotubes (CNTs) were supplied by Pyrograf Inc. This material consists of tubular fibers with an average diameter of $88 \pm 30 \mathrm{~nm}$ and a specific surface area of $55 \mathrm{~m}^{2} \mathrm{~g}^{-1}$. The oxygen-containing nanocarbon was obtained by treating the pristine CNTs with $\mathrm{HNO}_{3}$ according to the following procedure: a solution of CNTs in $\mathrm{HNO}_{3}$ concentrate (20 g of CNT per liter of $\mathrm{HNO}_{3}$ ) was kept at $373 \mathrm{~K}$ for $2 \mathrm{~h}$ under continuous stirring, then rinsed with distilled water, and finally dried at $343 \mathrm{~K}$ for several hours. N-containing CNTs were obtained from the pre-oxidized CNTs by thermal treatment of (10 g for each batch) with $\mathrm{NH}_{3}$ in the temperature range $473-873 \mathrm{~K}$ for $4 \mathrm{~h}$. The details of support functionalization have been published elsewhere. ${ }^{21}$

\subsection{Pd-based catalyst preparation}

$\mathrm{Na}_{2} \mathrm{PdCl}_{4}$ from Aldrich ( $99.99 \%$ purity), $\mathrm{NaBH}_{4}$ ( $>96 \%$ purity) from Fluka and polyvinyl alcohol (PVA) $\left(M_{\mathrm{w}}=13000-23000\right.$,
Table 1 Sample notation and details of the corresponding functionalization procedure

Sample Support characteristic $\quad \mathrm{N}^{a} \quad \mathrm{O}^{a}$

$\mathrm{Pd} / \mathrm{N}-\mathrm{CNT} 473 \mathrm{~K}$ CNTox functionalized by $\mathrm{NH}_{3}$ at $473 \mathrm{~K} \quad 12.3 \quad 11.7$ $\mathrm{Pd} / \mathrm{N}-\mathrm{CNT} 673 \mathrm{~K}$ CNTox functionalized by $\mathrm{NH}_{3}$ at $673 \mathrm{~K} 18.811 .7$ $\mathrm{Pd} / \mathrm{N}-\mathrm{CNT} 873 \mathrm{~K}$ CNTox functionalized by $\mathrm{NH}_{3}$ at $873 \mathrm{~K} \quad 8 \quad 3.4$ $\mathrm{Pd} / \mathrm{CNT}$ CNT functionalized by $\mathrm{HNO}_{3} \quad$ CN 23.3 $\begin{array}{llll}\mathrm{Pd} / \mathrm{CNT} & \text { Commercial carbon nanotube } & 1.3 & 6.7\end{array}$

${ }^{a}$ Surface elemental composition of the support in at $\%$ determined by XPS

$87-89 \%$ hydrolyzed) from Aldrich were used. First, aqueous solutions of PVA $(2 \%, w / w)$ and $\mathrm{NaBH}_{4}(0.1 \mathrm{M})$ were prepared.

$\mathrm{Na}_{2} \mathrm{PdCl}_{4} \cdot 2 \mathrm{H}_{2} \mathrm{O}(0.043 \mathrm{mmol})$ and PVA solution $(220 \mu \mathrm{l})$ were added to $130 \mathrm{ml}$ of $\mathrm{H}_{2} \mathrm{O}$. After $3 \mathrm{~min}, \mathrm{NaBH}_{4}$ solution $(860 \mu \mathrm{l})$ was added under vigorous magnetic stirring to the solution and a yellow-brown sol was immediately formed. The suspension was then acidified at $\mathrm{pH} 2$ by sulphuric acid and immobilized by adding the CNTs under vigorous stirring. The amount of support was calculated as having a final metal loading of $1 \mathrm{wt} \%$. After the immobilization, the samples were rinsed with distilled water and then dried in static air at $353 \mathrm{~K}$ overnight. In the following, the sample notation as reported in Table 1 will be used. Fresh samples are stored in air.

\subsection{Catalytic test: liquid phase oxidation of benzyl alcohol to benzaldehyde}

The reactions were carried out in a thermostatic glass reactor (30 ml) equipped with an electronically controlled magnetic stirrer. Gaseous oxygen from SIAD was $99.99 \%$ pure. The oxygen uptake was followed by a mass flow controller connected to a PC through an A/D board. The catalytic tests have been carried out under solventless conditions fixing the metal/ alcohol ratio to $1 / 3000 \mathrm{~mol} / \mathrm{mol}$ and the total volume at $10 \mathrm{ml}$. The reactor was pressurized at a pressure of $\mathrm{O}_{2}$ of 2 bar and thermostated at $353 \mathrm{~K}$. The reaction was initiated by stirring at a stirring rate of $1500 \mathrm{rpm}$. The effect of the alcohol/metal ratio on the activity of a highly active catalyst was previously studied to define the experimental conditions for the kinetic regime. ${ }^{22}$ Periodic sampling of the solution from the reactor was performed. Identification and analysis of the products were done by GC-MS and GC using a Dani 86.10 HT gas chromatograph equipped with a capillary column $(\mathrm{BP} 2130 \mathrm{~m} \times$ $0.53 \mathrm{~mm}, 0.5 \mu \mathrm{m}$ film; SGE). Quantification of the reactant products was done by the external calibration method.

\subsection{Catalyst characterization}

The Pd content was determined by X-ray fluorescence (XRF) spectroscopy using a wavelength dispersive $\mathrm{X}$-ray fluorescence (WDXRF) Bruker S4 Pioneer spectrometer. Typically, $0.5 \mathrm{~g}$ of sample were deposited inside a polystyrene holder $(34 \mathrm{~mm}$ in diameter) and covered with a $4 \mu \mathrm{m}$ polypropylene foil. The measurements have been performed under a He atmosphere.

A Hitachi S-4800 Scanning Electron Microscope (SEM) coupled with EDX detector for elemental analysis was used to investigate the surface morphologies of the nanoparticles and of the CNTs. All images were acquired using an acceleration 
voltage of $3 \mathrm{kV}$ for better resolution of surface features, and $15 \mathrm{kV}$ to investigate the inner cavity of the CNTs. The microstructure of the supports and the catalysts was investigated by Transmission Electron Microscopy (TEM). Highresolution transmission electron microscopy (HRTEM) and high angle annular dark field scanning transmission electron microscopy (HAADF-STEM) have been performed with a TitanCs300 microscope from FEI equipped with a Cs-corrector from CEOS. The samples were dry-deposited on a holey carbon film supported on a $\mathrm{Cu}$ grid.

The in situ XRD data were collected on a STOE Theta/theta $\mathrm{X}$-ray diffractometer $\left(\mathrm{CuK} \alpha_{1+2}\right.$ radiation, secondary graphite monochromator, scintillation counter) equipped with an Anton Paar XRK 900 in situ reactor chamber. The gas feed was mixed by means of Bronkhorst mass flow controllers, using helium as inert balance gas at a total flow rate of $100 \mathrm{ml} \mathrm{min} \mathrm{m}^{-1}$. The effluent gas composition was monitored with a Pfeiffer OmniStar quadrupole mass spectrometer.

$\mathrm{CO}$ and $\mathrm{H}$ chemisorption was carried out with the static volumetric method in a Quantachrome Autosorb 1C. Two isotherms at $313 \mathrm{~K}$ in the pressure range of $2.6 \times 10^{-3}-0.76 \mathrm{bar}$ were measured, the first with both the reversible and irreversible parts and the second with the reversible part only. In all cases the irreversibly chemisorbed $\mathrm{CO}$ amount is given. The mean surface area of a Pd atom is taken as $0.0787 \mathrm{~nm}^{2}$ per atom (DIN66).

A SETARAM MS70 Calvet calorimeter combined with a custom-designed high vacuum and gas dosing apparatus, which has been described in detail ${ }^{23}$ was used for the microcalorimetry investigation. Calibration of the heat-voltage constant of the microcalorimeter was accomplished by the Joule effect. Calibration of the volumes was carried out with $\mathrm{O}_{2}$ under the same conditions as for the adsorption procedure. We have adopted the calorimetric sign criterion (positive energetic quantity for an exothermic process). The dosing volume is $134 \mathrm{ml}$ and an absolute pressure transducer (MKS Baratron type 121) measures pressure variations of $0.003 \mathrm{hPa}$ within this volume, so that amounts as small as $0.03 \mu \mathrm{mol}$ can be dosed into the sample cell. The samples were tightly pressed into pellets and cut into small pieces. The sieved fraction with diameters between 0.40 and $0.60 \mathrm{~mm}$ was used. The sample pretreatment was carried out in the calorimeter under high vacuum at the reaction temperature of $353 \mathrm{~K}$ for $17 \mathrm{~h}$ to a final pressure of $6 \times 10^{-8} \mathrm{hPa}$. Afterwards, the sample cell was closed and subsequently oxygen was dosed stepwise into the initially evacuated cell. The pressure evolution and the heat signal were recorded for each dosing step until it reaches the baseline.

The adsorption isotherm was derived from the dosed amount and the equilibrium pressure (in comparison to an empty cell), and the differential heats were calculated by converting the signal area into a heat by using the calorimeter's calibration factor and then dividing the heat by the number of adsorbed oxygens in this step. The net amount of oxygen consumed at $353 \mathrm{~K}$ is expressed as micromoles of oxygen atoms per gram of catalyst. Therefore, normalization of differential heat of adsorption is done considering the oxygen atoms chemisorbed and consumed on the catalyst surface. The time constant of the calorimeter is estimated by calibration of the thermo signal using an ohm resistant at 250-300 s. If the time for the heat release of an individual adsorption step is higher than that of the calorimeter, a complex adsorption process can be assumed; otherwise, if the times are similar, a pure adsorption process is considered. The specific surface areas are determined by $\mathrm{O}_{2}$ chemisorption by applying Langmuir model with adsorption stoichiometry for $\mathrm{Pd}: \mathrm{O}_{2}=2: 1$ and crosssection area of $\mathrm{O}$ atom occupied by each active surface atom $\sim 0.07 \mathrm{~nm}^{2}$ (calculated from the Goldschmidt ionic radius $1.33 \AA$ for $\mathrm{O}$ ).

Two Pd based catalysts (Pd/N-CNT473K and Pd/N-CNT873K) with different catalytic behaviour were investigated by chemisorption. In order to simulate the reaction before chemisorption the samples were heated in water at the reaction temperature $(353 \mathrm{~K})$ and held at this temperature for $10 \mathrm{~min}$. Subsequently the samples were dried overnight at $353 \mathrm{~K}$. Prior to chemisorption the samples were outgassed for $17 \mathrm{~h}$ in a $\mathrm{He}$ flow at $353 \mathrm{~K}$. For comparison, a standard $\mathrm{Pd}_{\mathrm{wi}} / \mathrm{CNT}$ catalyst was investigated too. This catalyst was obtained by impregnation of the CNTs with $\mathrm{Pd}\left(\mathrm{NO}_{3}\right)_{2}$, followed by reduction in $\mathrm{H}_{2}$ at $423 \mathrm{~K}$ for $2 \mathrm{~h}$. It presents an average particle diameter of around $5 \mathrm{~nm}$. The pretreatment before chemisorption was $\mathrm{He}$ flow at $393 \mathrm{~K}$ for $2 \mathrm{~h}$, again reduction in $\mathrm{H}_{2}$ flow at $423 \mathrm{~K}$ for $30 \mathrm{~min}$ followed by $2 \mathrm{~h}$ evacuation.

A different pretreatment was chosen for the Pd/N-CNT473K and $\mathrm{Pd} / \mathrm{N}-\mathrm{CNT} 873 \mathrm{~K}$ samples (degassing at $353 \mathrm{~K}$ in $\mathrm{He}$ flow for $17 \mathrm{~h}$ ) to prevent structural modification.

\section{Results and discussion}

\subsection{Surface chemistry of CNTs}

The characterization of the surface chemistry of pristine and functionalized CNTs supports have been reported elsewhere. ${ }^{21}$ As summarized in Table 1, CNTs have a very low concentration of oxygen species and are consistently characterized by a hydrophobic surface. The treatment with nitric acid (CNTox) introduces mainly acidic and few basic oxygenated functionalities. The surface is acidic and presents a hydrophilic character. The supports functionalized with $\mathrm{NH}_{3}$ are characterized by the presence of a broad distribution of $\mathrm{O}$ and $\mathrm{N}$ species which is temperature dependent. At $473 \mathrm{~K}$ a bi-functional acidic and basic surface is obtained with high hydrophilic character. Treatment at higher temperature (673 K and $873 \mathrm{~K}$ ) causes the decomposition of the low thermally stable acidic species and thus the basicity and the hydrophobic character are enhanced. In particular, at $873 \mathrm{~K}$ stronger basic sites are introduced. After the metal immobilization, the catalysts show slightly acid character.

\subsection{Catalytic data in the benzyl alcohol oxidation to benzaldehyde}

The conversion of benzyl alcohol is plotted in Fig. 1 versus time for all the catalysts investigated under solventless conditions. Fig. 2 reports the moles of benzyl alcohol consumed per moles of $\mathrm{Pd}$ at 15 minutes of reaction and selectivity at $45 \%$ of conversion.

The functionalized CNTs under the same conditions were studied for comparison. The supports are not active for the reaction. But the functionalization of the CNTs with $\mathrm{N}$ or $\mathrm{O}$ 


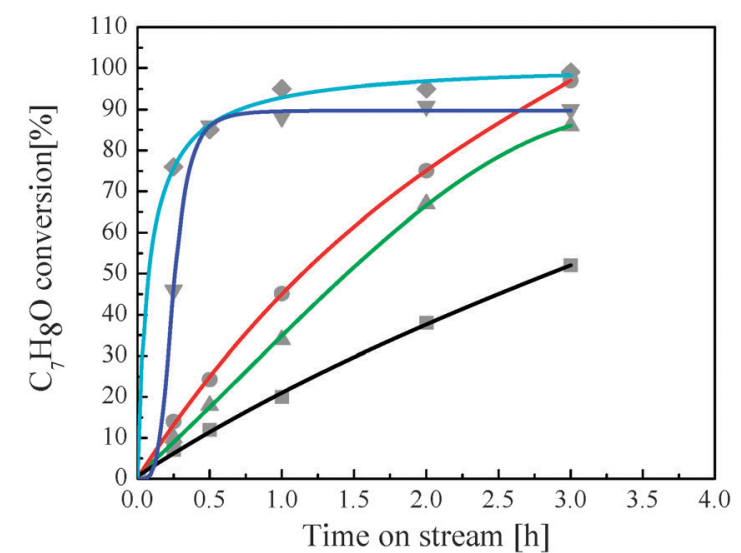

Fig. 1 Catalytic data in solventless conditions: conversion vs. reaction

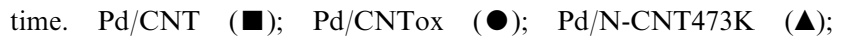
Pd/N-CNT673K $(\boldsymbol{\nabla}) ;$ Pd/N-CNT873K $(\bullet)$. Reaction conditions: benzyl alcohol/Pd molar ratio $3000, T=353 \mathrm{~K}, P_{\mathrm{O}_{2}}=2$ bar, stirring rate $1500 \mathrm{rpm}$.

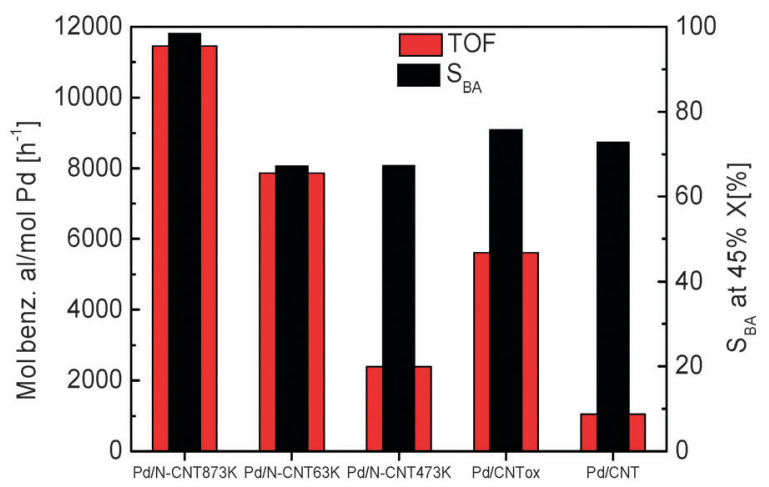

Fig. 2 Mol benzyl alcohol converted/mol total Pd loading (at $15 \mathrm{~min}$ reaction) and selectivity to benzaldehyde at $45 \%$ conversion. The number of mol of benzaldehyde at $45 \%$ conversion was extrapolated from the curve constructed by the experimental points measured.

species leads to better Pd-based catalyst than the Pd-based catalyst on the pristine CNTs. Among the catalysts investigated, the sample Pd/NCNT873K shows the best catalytic performance reaching almost total conversion after $30 \mathrm{~min}$ of reaction. The moles of benzyl alcohol consumed per moles of
$\mathrm{Pd}$ at 15 minutes of reaction is $11457 \mathrm{~h}^{-1}(75 \%$ conversion) while total selectivity to benzaldehyde at $45 \%$ conversion is estimated. The catalyst Pd/NCNT673K shows good initial activity even if slightly less selective to benzaldehyde ( $66 \%$ at $45 \%$ conv.).

Table 2 summarizes the moles of benzyl alcohol consumed per moles of $\mathrm{Pd}$ and selectivity to benzaldehyde at $90 \%$ conversion for all the catalysts investigated in this work and compares with literature data.

From Table 2, it can be seen that at $90 \%$ conversion the selectivity to benzaldehyde of the Pd-based catalyst approaches a similar value of around $70 \%$ accordingly to the value reported in the literature. Under solventless conditions, $\mathrm{N}$-functionalization of the CNT support leads to similar or higher moles of benzyl alcohol consumed per moles of Pd than Pd/PR24PS ${ }^{14}$ but under milder conditions.

The selectivity to benzaldehyde for all the catalysts at the end of the reaction is shown in Table 3. At the end of the reaction, the catalysts show quite high and similar selectivity to benzaldehyde, with toluene as the main unselective hydrogenation by-product and, in smaller amounts benzoic acid and benzyl benzoate as unselective oxidation by-products.

Several studies ${ }^{25-28}$ have shown that toluene is a co-product of the benzaldehyde formed on reduced Pd even in the absence of $\mathrm{O}_{2}$, through dehydrogenation of benzyl alcohol which leads to the formation of adsorbed hydrogen. Thus in this case the benzyl alcohol acts as a hydrogen acceptor leading to toluene formation. This is the so-called benzyl alcohol disproportionation pathway.

In the presence of $\mathrm{O}_{2}$, the rate of benzaldehyde formation increases due to the fact that the $\mathrm{O}_{2}$ is a much better hydrogen acceptor than benzyl alcohol. Also the successive hydrogenolysis-decarbonylation of benzaldehyde to benzene should be considered. ${ }^{29}$ Thus, removal of the hydrogen formed in the rapid dehydrogenation step addresses the selectivity issue. ${ }^{29}$

In general, under solventless conditions, the higher benzyl alcohol concentration at the metal surface with respect to the surface oxygen concentration leads to hydrogenolysis at the expense of the selective oxidation. ${ }^{29}$ This is consistent with the observed increased selectivity to benzaldehyde (above 90\%) for all the samples when the reaction is carried out in aqueous solution (Table S1, ESI $\dagger$ ).

Considering that the main secondary pathway is the parallel disproportionation reaction of benzyl alcohol, while the

Table 2 Catalytic data in solventless conditions: comparison with literature data

\begin{tabular}{|c|c|c|c|c|c|c|}
\hline Sample & $\operatorname{TOF}^{a}\left(\mathrm{~h}^{-1}\right)$ & Selectivity at $90 \%$ conv. $(\%)$ & Substrate/metal ratio $\left(\mathrm{mol} \mathrm{mol}^{-1}\right)$ & $T$ and $P_{\mathrm{O}_{2}}$ & Solvent & \\
\hline $\mathrm{Pd} / \mathrm{NCNT} 873 \mathrm{~K}$ & 11457 & 71 & $3000 / 1$ & $353 \mathrm{~K} ; 2$ bar & Solventless & This work \\
\hline $\mathrm{Pd} / \mathrm{NCNT} 673 \mathrm{~K}$ & 7865 & 66 & & & & \\
\hline $\mathrm{Pd} / \mathrm{NCNT} 473 \mathrm{~K}$ & 2387 & - & & & & \\
\hline $\mathrm{Pd} / \mathrm{CNT}$ ox & 5621 & 75 & & & & \\
\hline $\mathrm{Pd} / \mathrm{CNT}$ & 1049 & - & & & & \\
\hline $\mathrm{Pd} / \mathrm{AC}$ & 1482 & 74 & $3000 / 1$ & $353 \mathrm{~K} ; 2$ bar & Cyclohexane & 24 \\
\hline $\mathrm{Pd} / \mathrm{CNT}$ & 1390 & 92 & & & & \\
\hline $\mathrm{Pd} / \mathrm{PR} 24 \mathrm{PS}^{b}$ & 7260 & 62 & $35000 / 1$ & $393 \mathrm{~K} ; 1.5$ bar & Solventless & 14 \\
\hline $\mathrm{Pd} /$ Baytube & 43281 & 62 & & & & \\
\hline $\mathrm{Pd} / \mathrm{N}-\mathrm{PR} 24 \mathrm{Ps}$ & 65876 & 64 & & & & \\
\hline $\mathrm{Pd} / \mathrm{N}$-Baytube & 50387 & 68 & & & & \\
\hline $\mathrm{Pd} / \mathrm{AC}$ & 47834 & 67 & & & & \\
\hline
\end{tabular}


Table 3 Selectivity at maximum conversion under solventless conditions as reported in Fig. 1

\begin{tabular}{lllllll}
\hline & \multicolumn{7}{l}{ Selectivity at maxim conversion after 3 h reaction (\%) } & & \\
\cline { 2 - 7 } Catalyst & Benzene & Toluene & Benzaldehyde & Benzoic acid & Benzyl benzoate & Unknown \\
\hline Pd/NCNT873K & 0.8 & 18.8 & 76.0 & 2.7 & 1.2 & 0.5 \\
Pd/NCNT673K & 2.4 & 19.0 & 73.3 & 2.9 & 1.9 & 0.5 \\
Pd/NCNT473K & 5.3 & 22.8 & 68.7 & 3.5 & 4.4 & 0.0 \\
Pd/CNTox & 3.1 & 13.1 & 75.3 & 3.2 & 0.6 & 0.6 \\
Pd/CNT & 4.3 & 17.6 & 74.4 &
\end{tabular}

successive secondary reaction pathways are negligible (Table 3), the decreasing of the selectivity to benzaldehyde from $99 \%$ at $45 \%$ conversion (Fig. 2) to $71 \%$ at $90 \%$ conversion (Table 2) to $76 \%$ at $99 \%$ conversion (Table 3) for the sample $\mathrm{Pd} / \mathrm{NCNT} 873 \mathrm{~K}$ indicates that the $\mathrm{Pd}$ nanoparticles nanostructure has changed during the reaction. In fact, HAADFSTEM in Fig. 4 has shown some sintering of the $\mathrm{Pd}$ nanoparticles upon washing at $353 \mathrm{~K}$ while only a part of the small nanoparticles is preserved. Similar decrease of selectivity due to disproportionation reaction was already reported and attributed to an induction period in which the sites responsible for the disproportionation are formed. ${ }^{29}$

As was already reported in the literature, ${ }^{30}$ the particle size and morphology control the surface $\mathrm{O}$ chemisorption and subsurface dissolution as well as the benzyl alcohol adsorption, through a feed-back mechanism that influences the reactivity. As will be shown later on by means of TEM and XRD characterization of the Pd/NCNT873K and Pd/NCNT473K, the support induces the morphology and the nanostructure of the $\mathrm{Pd}$ nanoparticles, resulting in a different catalytic performance. For the $\mathrm{Pd} / \mathrm{NCNT} 473 \mathrm{~K}$, already at $45 \%$ conversion the selectivity to benzaldehyde is around $70 \%$ and therefore the sites responsible for the disproportionation are already present or formed earlier.

Additionally, the carbon overlayer controls the selectivity by influencing the surface nanostructure and the different adsorption geometry of the reacting molecule. For instance larger particles might allow two adjacent benzyl alcohol molecules to chemisorb. The adsorption-induced detachment of the PVA units on the nanoparticles not strongly stabilized at the carbon surface destabilizes the nanoparticles and leads to the sintering. This accounts for the observed changes in selectivity with time.

\subsection{Morphology and structure of the Pd nanoparticles}

The influence of the surface chemistry of CNTs can be observed at different scale on morphology ${ }^{31}$ and nanoparticles stability.

Secondary electron (SE) and back-scattered electron (BSE) scanning electron microscopy (SEM) images of the sample $\mathrm{Pd} / \mathrm{CNT}$ show a zone with higher particles density and agglomerations (Fig. S1, ESI $\dagger$ ).

Similarly, the HAADF-STEM pictures for the sample $\mathrm{Pd} / \mathrm{N}-\mathrm{CNT} 473 \mathrm{~K}$ (Fig. S2a, ESI $\dagger$ ) and the sample $\mathrm{Pd} / \mathrm{N}$ CNT873K (Fig. S2b, ESI $\dagger$ ) show Pd nanoparticles well dispersed over the CNTs surface. However, some tubes present higher particles density and in some cases particles agglomeration is observed. For the catalyst Pd/N-CNT473K, particles agglomeration is more pronounced as shown in Fig. S2a, ESI. $\dagger$
Table 4 Metal loading and particles size distribution

\begin{tabular}{llllll}
\hline Sample & $\begin{array}{l}\text { Pd/N- } \\
\text { CNT673K }\end{array}$ & $\begin{array}{l}\text { Pd/N- } \\
\text { CNT873K }\end{array}$ & $\begin{array}{l}\text { Pd/ } \\
\text { CNTox }\end{array}$ & $\begin{array}{l}\text { Pd/N- } \\
\text { CNT473K }\end{array}$ & CNT $/$ \\
\hline $\mathrm{Pd}^{a} / \mathrm{wt} \%$ & 0.7 & 0.8 & 0.3 & 0.5 & 0.8 \\
$d^{b} / \mathrm{nm}$ & $3.3 \pm 0.7$ & $2.7 \pm 0.6$ & $3.2 \pm 0.8$ & $4.3 \pm 1.2$ & $3.6 \pm 0.6$ \\
Aspect-ratio & $1.4 \pm 0.4$ & $1.4 \pm 0.5$ & $1.0 \pm 0.3$ & $1.1 \pm 0.3$ & $1 \pm 0.2$ \\
${ }^{a}$ Determined by XRF. & \\
is & Average diameter; for non-spherical particles \\
is the larger length.
\end{tabular}

The average particle size diameter (major length for nonspherical particles) determined by statistical measurements in HRTEM images ranges between 2-4 nm. In particular, as reported in Table 4, the average particles size is about $2.7 \mathrm{~nm}$ for N-CNT873K, $3.2 \mathrm{~nm}$ for N-CNT673K, $4.3 \mathrm{~nm}$ for N-CNT473K, $3.3 \mathrm{~nm}$ on Pd/CNTox and $3.6 \mathrm{~nm}$ on Pd/CNT. Such a value is slightly higher than the average particle size observed on the sol $(2.7 \mathrm{~nm}$, Fig. S3, ESI $\dagger)$. A different $\mathrm{Pd}$ loading was measured by XRF for the different samples. Hydrophobic support such as CNT, N-CNT673K and $\mathrm{N}-\mathrm{CNT} 873 \mathrm{~K}$ give rise to higher Pd loading, approaching the theoretical $1 \%$ wt (in Table $40.8 \%, 0.7 \%, 0.8 \%$ respectively) than the support with comparatively more hydrophilic character. In fact, the metal loading is about $0.3 \%$ wt and $0.5 \% \mathrm{wt}$ for the CNTox and N-CNT473K, respectively, though the Pd available in solution is the same.

HRTEM investigations on the Pd based catalysts show nanoparticles with different morphology (Fig. 3a). Very small particles approaching cluster dimension (1), decahedron along the 5-fold symmetry axis (2) cuboctahedron particles (3) and raft-like particles (4) are found. Fig. 3b shows a PVA-encapsulated MTP. The direct interaction of the particles with the surface of CNTs is hindered by the interfacial carbon shell, which preserves the particle shape. However, in some parts the naked metal surface is exposed as indicated by the arrow. Fig. 3c shows a particle accommodated at the carbon surface for the sample Pd/N-CNT873K.

Obviously, the particles morphology and nanostructure at the surface are affected as they accommodate at the carbon surface: the $\mathrm{Pd}$ surface atoms migrate to form high index faceting $^{20,31,33}$ (steps and kinks) as shown in Fig. 3c. These are low-coordinative sites and thus are considered the most relevant for the reactivity. ${ }^{34,35}$

Several examples of HRTEM images of nanoparticles immobilized at the CNT surface and the corresponding FFT are reported in the ESI $\dagger$ (Fig. 4S). The inhomogeneity of the particles size and morphology on the same sample (very pronounced for $\mathrm{Pd} / \mathrm{N}-\mathrm{CNT} 473 \mathrm{~K}$ ) reflects the local different surface chemistry of the carbon support. 


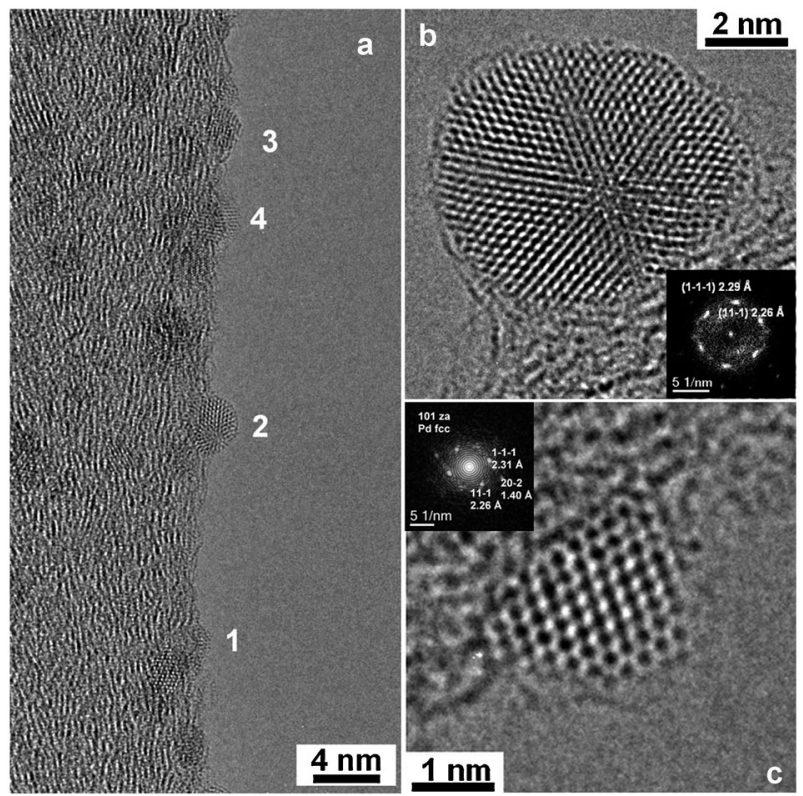

Fig. 3 (a) HRTEM for Pd on N-CNT873K; HRTEM for sample $\mathrm{Pd} / \mathrm{CNT}$ (b); HRTEM image for sample Pd/N-CNT873K (c).

On the basis of the result presented, the role of the surface chemistry of the $\mathrm{C}$ support can be addressed.

During the immobilization, the chemical affinity of the carbon surface with the PVA-wrapped metal nanoparticles rules out the nanoparticles adsorption-deposition at the carbon surface and determines the metal loading.

Based on the fact that a hydrophilic carbon surface leads to low loading and particles agglomeration (Fig. S4f, ESI $\dagger$ ), we may assume that those are hydrophobic-hydrophobic interactions. If a strong hydrophobic-hydrophobic interaction between the carbon surface and PVA is realized, a partial deprivation of the protective PVA-shell occurs and results in certain mobility of the metal atoms at the carbon surface.

We have previously reported ${ }^{21}$ that the $\mathrm{NH}_{3}$ functionalization leads to the formation of specific functionalities on the carbon surface which are maximised at $873 \mathrm{~K}$, i.e. very strong basic sites containing $\mathrm{O}$ and $\mathrm{N}$ atoms in hetero-cycle conjugated structure. ${ }^{32} \mathrm{We}$ assume that very small nanoparticles are indeed stabilized at these sites. ${ }^{19,20}$

The as-received CNT realizes a good support-PVA interaction ( $0.8 \%$ Pd loading) but the low concentration of functional sites leads, during the immobilization, to overgrowth of the MTP (Fig. 3a) or agglomeration (Fig. S4f, ESI $\dagger$ ).

This is also supported by the HAADF-STEM on the sample washed Pd/N-CNT873K (Fig. 4) which shows clearly some sintering of the particles; however some of the very small ones are still preserved, which indicates that they were strongly stabilized at specific sites.

Macroscopically, the metal-support interaction can be evaluated by the enhanced metal wetting. Small particles better wet the carbon surface resulting in oval-like particles rather than the round particle shape observed in colloids. Particles spread on the CNTs surface, named "raft" nanoparticles, are also observed and they occur as a consequence of the strong metal-support interaction.

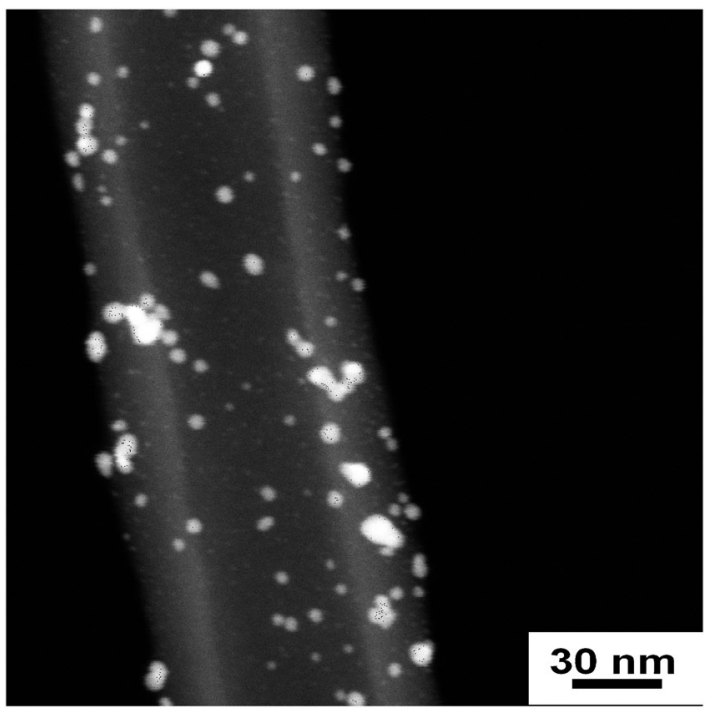

Fig. 4 HAADF-STEM of washed Pd/N-CNT873K.

In order to define numerically the entity of the metal wetting, statistic measurements of the aspect ratio of the particles on different supports have been carried on. The particle aspect ratio is, by definition, the ratio between the length and the height of the particle and gives quantitative information about the divergence of the particle shape from the spherical situation which is defined by an aspect ratio equal to 1 . This represents indirectly a measure of the metal-support interactions. The values are summarized in Table 4. Accordingly, the samples $\mathrm{Pd} / \mathrm{N}-\mathrm{CNT} 873 \mathrm{~K}$ and $\mathrm{Pd} / \mathrm{N}-\mathrm{CNT} 673 \mathrm{~K}$ present higher population of particles with aspect ratio larger than 1. The aspect ratio may be underestimated, as in the statistical measurements raft particles could not be included.

The expansion of the $\mathrm{Pd}$ structure is associated ${ }^{36-38}$ to the presence of interstitial $\mathrm{C}$ impurities which may migrate into the $\mathrm{Pd}$ phase during the catalyst preparation from the carbon overlayer or from the functional group of the carbon support. Also expansion of the fcc structure for Pd nanoparticles could be due also to dissolved $\mathrm{O}$. However, oxidized $\mathrm{Pd}$ might undergo chemical reduction induced by the electron beam in the electron microscope. Therefore, $\mathrm{Pd}$ nanoparticles showing a metallic fcc structure by HRTEM might have contained oxygen dissolved in the structure before entering the microscope. ${ }^{39}$

Therefore, the structure of the nanoparticles for two $\mathrm{Pd} /$ N-CNT873K and Pd/N-CNT473K was also studied by in situ XRD. Fig. 5a reports the XRD patterns of the fresh sample $\mathrm{Pd} / \mathrm{N}-\mathrm{CNT} 873 \mathrm{~K}$ at $298 \mathrm{~K}$ under helium (red), then under 5\% $\mathrm{H}_{2}$ (green) and $\mathrm{He}$ (blue) again. Due to overlap with the complex background signal from the CNT support (black curve), the Pd-related peaks become only obvious when comparing the XRD patterns of the metallic and hydride states with each other. The initial pattern in He shows reflection peaks typical of metallic $\mathrm{Pd}$ although broad due to the small particle size. The exposure to $\mathrm{H}_{2}$ leads to lattice expansion as a consequence of the $\mathrm{PdH}_{x}$ formation (4-4.5\%). The process is reversible and by switching back to the He atmosphere the metallic Pd phase is restored. The XRD patterns of the fresh sample $\mathrm{Pd} / \mathrm{N}-\mathrm{CNT} 473 \mathrm{~K}$ at $298 \mathrm{~K}$ under helium (red), then under $5 \% \mathrm{H}_{2}$ (green) and $\mathrm{He}$ (blue) again are reported in Fig. $5 \mathrm{~b}$. 

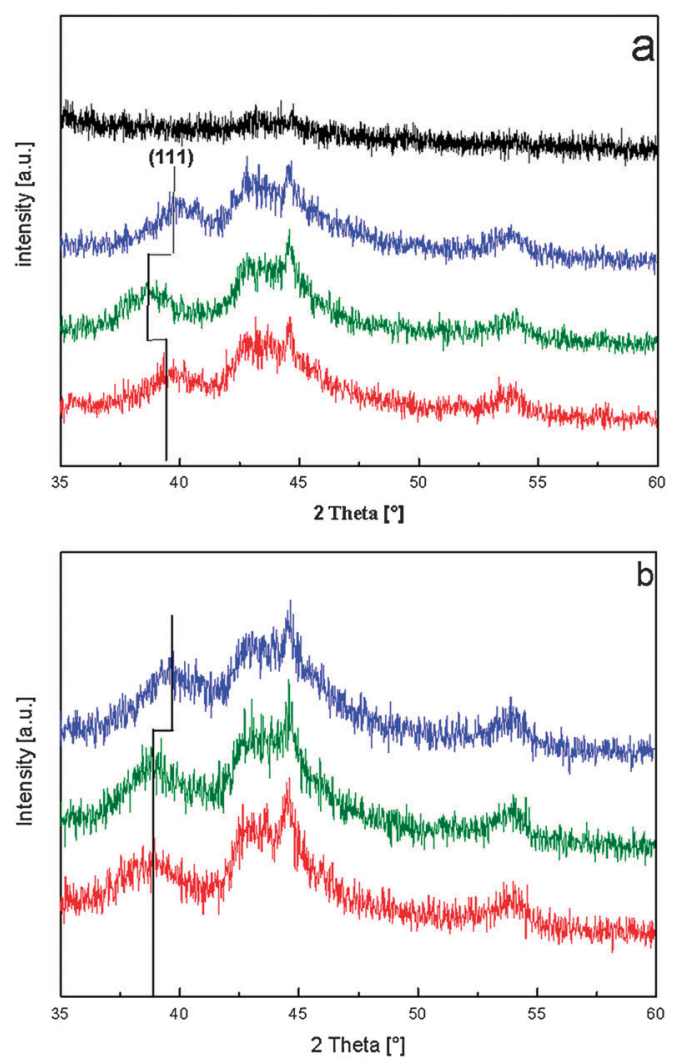

Fig. 5 In situ XRD on Pd/N-CNT873K (a); Pd/N-CNT473K (b). 1st step (red curve): He at R.T.; 2nd step (green curve): $\mathrm{H}_{2}$ at R.T.; 3rd step (blue curve): He at R.T.; CNT (black curve).

Conversely, the Pd-related XRD patterns show already as initial state the expansion similar to the one under $\mathrm{H}_{2}$, while switching back to He produces shrinkage of the structure which can be assumed as a metallic phase. Small nanoparticles relatively strongly interacting at the carbon surface in $\mathrm{Pd} / \mathrm{N}$ CNT873K are characterized by $\mathrm{Pd}$ nanoparticles with a metallic structure, while the bigger nanoparticles less interacting at the carbon surface in $\mathrm{Pd} / \mathrm{N}-\mathrm{CNT} 473 \mathrm{~K}$ are more susceptible to dissolve heteroatoms already on the fresh sample. Therefore it is obvious that the surface chemistry of the support influences the morphology and the surface/subsurface structure of the $\mathrm{Pd}$ nanoparticles in the fresh sample, thus influencing the reaction kinetics and pathways.

\subsection{Reaction with oxygen and hydrogen on $\mathrm{Pd}_{\mathrm{wi}} / \mathrm{CNT}$ and washed $\mathrm{Pd} / \mathrm{N}-\mathrm{CNT873K}$ and Pd/N-CNT473K}

The reactivity of oxygen with the Pd samples was investigated by microcalorimetry at the reaction temperature used for the benzyl alcohol oxidation, $353 \mathrm{~K}$. The Pd samples obtained via immobilization are compared to a PVA-free Pd reference sample $\left(\mathrm{Pd}_{\mathrm{wi}} / \mathrm{CNT}\right)$ obtained by incipient wetness impregnation. This is necessary due to the complex profile and the very high differential heat registered for the investigated samples, which requires the knowledge of the energetic profile of the oxygen interaction at the Pd surface.

The differential heat of oxygen chemisorption versus the oxygen coverage is plotted for the reference sample in Fig. 6. Accordingly, the catalyst $\mathrm{Pd}_{\mathrm{wi}} / \mathrm{CNT}$ gives rise to an initial

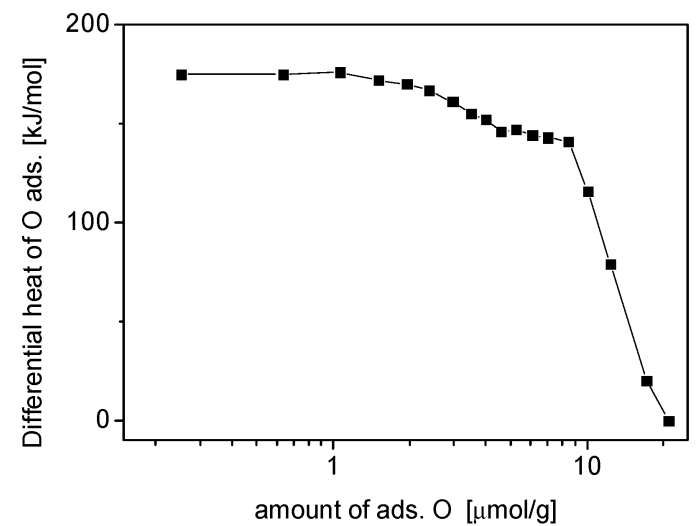

Fig. 6 Differential heat of dissociative $\mathrm{O}_{2}$ adsorption versus the amount of $\mathrm{O}_{2}$ uptake for the sample $\mathrm{Pd}_{\mathrm{wi}} / \mathrm{CNT}$; the connection of the point indicates the order of the experiments.

differential heat of $175 \mathrm{~kJ} \mathrm{~mol}^{-1}$. The differential heat signal exhibits a plateau form with the increase of the oxygen uptake up to the coverage of $4 \mu \mathrm{mol} \mathrm{g}{ }^{-1}$ and afterwards it decreases to a value of $140 \mathrm{~kJ} \mathrm{~mol}^{-1}$. A second plateau is observed up to $8.4 \mu \mathrm{mol} \mathrm{g}^{-1}$, and afterwards the differential heat decreases gradually until no further thermal signal is recorded at the amount of oxygen uptake of $21 \mu \mathrm{mol} \mathrm{g}{ }^{-1}$. Such a plateau was already described in the literature for oxygen chemisorption on metal and attributed to a "layering effect". 40 The value of $140 \mathrm{~kJ} \mathrm{~mol}^{-1}$ was also reported in the literature ${ }^{41}$ for the oxygen chemisorption on the $\mathrm{Pd} / \mathrm{SiO}_{2}$ catalyst at $313 \mathrm{~K}$. Therefore the $8.4 \mu \mathrm{mol} \mathrm{\textrm {g } ^ { - 1 }}$ can be assumed as the surface saturation coverage. Indeed, the initial value is too high for pure chemisorption on Pd. Although studies of the chemisorption of oxygen on supported nanoparticles have shown that the heat of dissociative adsorption increases when the crystallite size decreases $^{42}$ the particles size of this sample is rather broad and ranges between 5-20 $\mathrm{nm}$, and therefore the differential heat rather independent of the particles size. We rather believe that such a value is affected by reaction which involves impurities (i.e. $\mathrm{CH}$ or $\mathrm{COH}$ impurities) rather than size effect. The specific surface area determined at the saturation coverage for $\mathrm{O}, \mathrm{CO}$ and $\mathrm{H}$ chemisorption is reported in Table 5. The oxygen adsorption isotherm is reported in Fig. S5, ESI. $\dagger$ The reference sample is characterized by a profile very well fitted with the Langmuir adsorption model and results in the accessible Pd metal surface area of $\sim 2 \mathrm{~m}^{2} \mathrm{~g}^{-1}$. The specific surface area determined by $\mathrm{CO}$ chemisorption is $1 \mathrm{~m}^{2} \mathrm{~g}^{-1}$ in good agreement with the theoretical calculated surface area, assuming semi-spherical exposed Pd particles

Table 5 Specific surface area by chemisorption

\begin{tabular}{llll}
\hline & \multicolumn{3}{l}{ Specific surface area $/ \mathrm{m}^{2} \mathrm{~g}^{-1}$} \\
\cline { 2 - 4 } Sample & $S_{\mathrm{O}}$ & $S_{\mathrm{CO}}$ & $S_{\mathrm{H}}$ \\
\hline $\mathrm{Pd}_{\mathrm{wi}} / \mathrm{CNT}$ & 2 & 1 & 2.1 \\
$\mathrm{Pd} / \mathrm{N}-C N T 873 K$ Kashed & $0.7^{a}$ & 0.39 & 4.3 \\
Pd/N-CNT473Kwashed & $1.2^{a}$ & 0.25 & 2.2
\end{tabular}

${ }^{a}$ The $\mathrm{O}_{2}$ surface was determined assuming the Tempkin model. $\mathrm{O}_{2}$ reactive microcalorimetry was determined at $353 \mathrm{~K}$; $\mathrm{CO}$ and $\mathrm{H}$ chemisorption was carried out at R.T. 
$\left(1 \mathrm{~m}^{2} \mathrm{~g}^{-1}\right)$ with average particle diameter from TEM statistical measurements.

The difference between $S_{\mathrm{H}}, S_{\mathrm{O}}$ and $S_{\mathrm{CO}}$ accounts for the parts of metal surface covered with $\mathrm{C}$ impurities which are not accessible to $\mathrm{CO}$ but to $\mathrm{H}$. In the case of $S_{\mathrm{O}}$, the amount of oxygen penetrated into the subsurface as well as the metal surface area freed during the combustion of the $\mathrm{C}$ impurities contribute to the surface area.

This is strongly supported by the heat evolution kinetics in Fig. 7a. In fact, in the initial pulses the time for the heat release (30 min) is longer than the calorimeter response and this is normally due to secondary processes. ${ }^{43}$

At the surface saturation coverage, the repulsion between $\mathrm{O}_{\mathrm{ads}}$ atoms reduces the chemisorbed oxygen atom-palladium surface bond energy and allows the subsurface oxygen chemisorption. ${ }^{42-53}$ At this point, the peak is composed of two-overlapping components: the first heat signal is quite sharp and the following signal is diffuse. The appearing of the second diffuse peak in the integral heat peak profile can be thus related to the following subsurface oxygen dissolution. Oxygen chemisorption was not observed on the fresh $\mathrm{Pd} /$ $\mathrm{N}-\mathrm{CNT} 873 \mathrm{~K}$ and Pd/N-CNT473K catalysts at $353 \mathrm{~K}$. This indicates that the active sites for the oxygen chemisorption are blocked by the PVA.

To investigate the oxygen chemisorption on the Pd samples, a thermal pretreatment at $353 \mathrm{~K}$ in water was necessary. The samples subjected to this pretreatment are referred to in the text as washed samples. This pretreatment can be considered as simulating the reaction and the catalyst surface as its state after 10 min reaction.

The initial differential heat recorded for the washed sample $\mathrm{Pd} / \mathrm{N}-\mathrm{CNT} 873 \mathrm{~K}$ is $518 \mathrm{~kJ} \mathrm{~mol}^{-1}$ (Fig. 8). A second pulse of oxygen produces a strong increase of the differential heat released up to $725 \mathrm{~kJ} \mathrm{~mol}^{-1}$ which oscillates around these maximum and minimum values with increase in the coverage. The high differential heat calculated is certainly related to combustion reaction, which characterizes both samples ${ }^{43}$ i.e. reacting $\mathrm{C}-\mathrm{OH}$ species of the carbon overlayer (Fig. 8). For instance, the 2nd pulse of oxygen for the sample $\mathrm{Pd} / \mathrm{N}-\mathrm{CNT} 873 \mathrm{~K}$ shows a higher heat released than the 1 st and 3rd pulse but the amount of oxygen irreversibly consumed did not increase proportionally (Table S2, ESI $\dagger$ ). We can assume that, at this point, the $\mathrm{CO} / \mathrm{CO}_{2}$ produced through the combustion was released and contributed to the equilibrium pressure.

Therefore, the heat released is the sum of chemisorption and oxidation. This is referred to more properly as differential heat of reaction and as irreversible oxygen consumption to differentiate from the oxygen converted in the reaction and contributing to the equilibrium pressure. Above $5 \mu \mathrm{mol} \mathrm{g} \mathrm{g}^{-1}$ the surface saturation of the catalysts is achieved.

The profile of the differential heat of reaction versus oxygen consumption for the washed Pd/N-CNT473K shows a similar oscillating trend as the $\mathrm{Pd} / \mathrm{N}-\mathrm{CNT} 873 \mathrm{~K}$ catalyst, however the maximum value is lower. The saturation concentration, before that the differential heat of chemisorption decreases, is $17 \mu \mathrm{mol} \mathrm{g}^{-1}$ of $\mathrm{O}$ consumed.

The specific surface areas determined by $\mathrm{O}, \mathrm{CO}$ and $\mathrm{H}$ are reported in Table 5 for these samples as well.
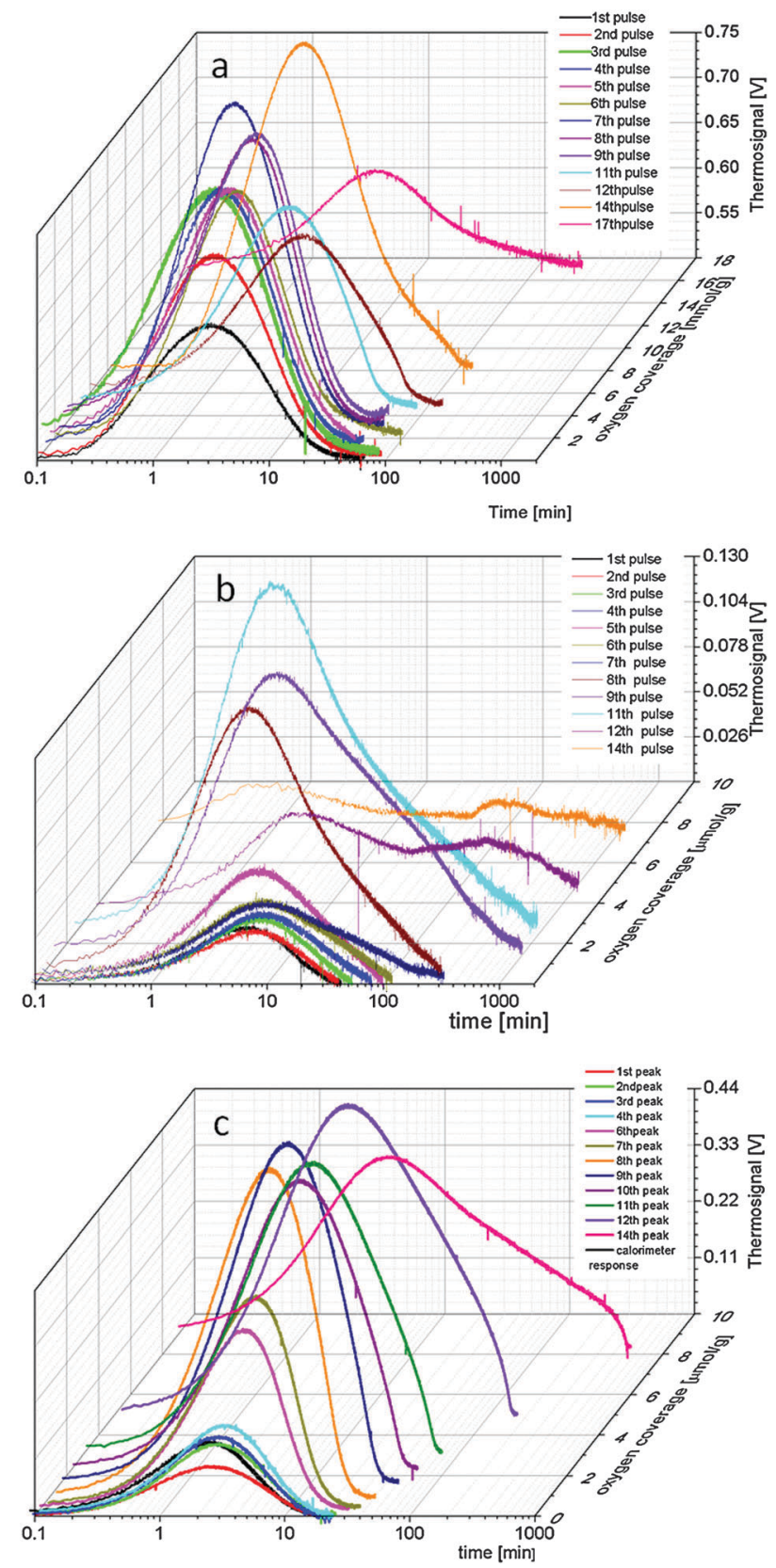

Fig. 7 Integral heat signal versus time at different coverage for the sample $\mathrm{Pd}_{\mathrm{wi}} \mathrm{CNT}$. Selected pulses corresponding to the points plotted in Fig. 6 are reported (a); integral heat signal versus time at different coverage for the sample $\mathrm{Pd} / \mathrm{N}-\mathrm{CNT} 873 \mathrm{~K}$ (b); integral heat signal versus time at different coverage for the sample $\mathrm{Pd} / \mathrm{N}-\mathrm{CNT} 473 \mathrm{~K}$. Selected pulses corresponding to the points plotted in Fig. 8 are reported. Additionally the calorimeter response for the heat released is plotted as a black line (15 $\mathrm{min})(\mathrm{c})$.

For Pd/N-CNT873K and Pd/N-CNT473K washed, however, the isotherms for the O chemisorption (Fig. S5, ESI $\dagger$ ) do not fit very well with the Langmuir model and they can be considered as a superimposition of several uptake curves due to several processes occurring. CO chemisorption on these two catalysts gives a specific metal surface area of 0.39 and $0.25 \mathrm{~m}^{2} \mathrm{~g}^{-1}$ for Pd/N-CNT873K and Pd/N-CNT473K respectively. These values differ strongly from the expected theoretical 


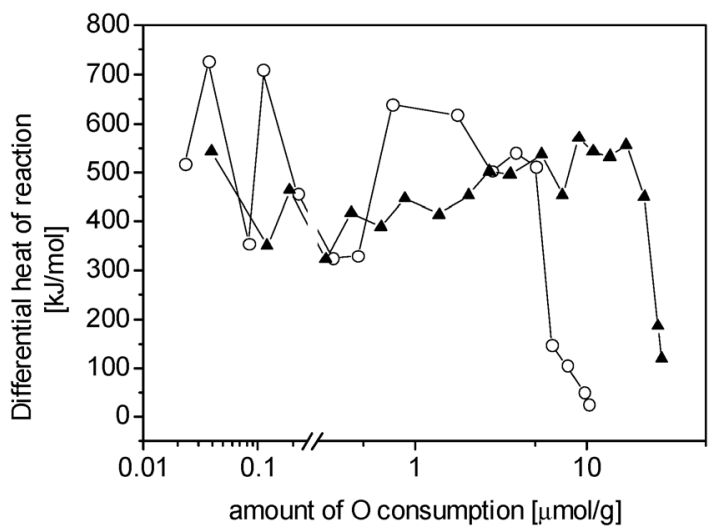

Fig. 8 Differential heat of reaction versus the amount of $\mathrm{O}_{2}$ consumed for the samples Pd/N-CNT873K $(\bigcirc)$ and Pd/N-CNT473K $(\boldsymbol{\Delta})$; the connection of the point indicates the order of the experiments.

surface area for Pd particles with the average diameter as measured by HRTEM assuming semispherical exposed surface, $1.8 \mathrm{~m}^{2} \mathrm{~g}^{-1}$ and $1.2 \mathrm{~m}^{2} \mathrm{~g}^{-1}$, respectively. This discrepancy is due to the fact that part of the metal surface is covered by the PVA.

The kinetics of the integral heat release (Fig. 7b and $\mathrm{c}$ for the samples $\mathrm{Pd} / \mathrm{N}-\mathrm{CNT} 873 \mathrm{~K}$ and $\mathrm{Pd} / \mathrm{N}-\mathrm{CNT} 473 \mathrm{~K}$, respectively) gives additional information.

The integral heat signal developed at the 1st pulse (Fig. 7b) is characterized by a time of heat release of about $40 \mathrm{~min}$, significantly higher than the time of the heat release for the calorimeter heat signal calibration $(\sim 15 \mathrm{~min})$. As the consumption increases, the time for the heat release increases and close to the saturation concentration (14th pulse), the peak shape is extremely broad ( $800-1000 \mathrm{~min})$ and is due to at least two-overlapped integral heat signals. The sample $\mathrm{Pd} / \mathrm{N}$ CNT473K is characterized at the 1 st pulse, by fast heat release (13 $\mathrm{min}$ ). Only above $9 \mu \mathrm{mol} \mathrm{g}^{-1}$ of oxygen uptake, the time for the integral heat release considerably increases to $381 \mathrm{~min}$ (14th pulse), indicating a different process. Again, this can be clearly seen in the integral peak shape which can be roughly considered to be composed of at least two peaks. The sample Pd/N-CNT873K shows dramatic delay of the integral heat release at much lower oxygen consumption than the sample $\mathrm{Pd} / \mathrm{N}-\mathrm{CNT} 473 \mathrm{~K}$. In analogy to the reference sample, the delay of the integral heat release for Pd/N-CNT873K can be attributed to subsurface processes. This is consistent with the in situ XRD investigation that addresses for lattice expansion due to near surface dissolved impurities on the $\mathrm{Pd} / \mathrm{N}-\mathrm{CNT} 473 \mathrm{~K}$ while this is not the case for the $\mathrm{Pd} / \mathrm{N}-\mathrm{CNT} 873 \mathrm{~K}$. Therefore, we might conclude that the $\mathrm{Pd} / \mathrm{N}-\mathrm{CNT} 873 \mathrm{~K}$ near the surface region is not saturated and therefore is more susceptible to undergo dynamic surface/subsurface processes during the microcalorimetry experiment.

The oscillation of the differential heat can be understood on both the Pd/N-CNT873K and Pd/N-CNT473K as free active sites are further generated at higher oxygen consumption due to the dynamic situation generated by the cleaning effect of oxygen removing $\mathrm{C}-\mathrm{OH}$ species. ${ }^{54}$ After every calorimetric experiment, the calorimetric sample cell was degassed by pumping (final pressure $10^{-8}$ mbar) at $353 \mathrm{~K}$ in order to measure the integral desorption heat of oxygen (negative energetic quantity for an endothermic process). The investigated samples did not show any endothermic integral desorption heat signal as expected for irreversible interaction of oxygen with the surface sites.

Table 5 summarizes the specific surface area determined by $\mathrm{H}_{2}$ as well. Also the $\mathrm{H}_{2}$ chemisorption on the washed samples gives a different specific surface area compared to $\mathrm{CO}$ although the trend is the same. As shown by $\mathrm{XRD}, \mathrm{H}_{2}$ molecules can penetrate the PVA shell of the fresh $\mathrm{Pd} / \mathrm{N}-\mathrm{CNT} 873 \mathrm{~K}$, while $\mathrm{CO}$ and $\mathrm{O}_{2}$ cannot. We can therefore assume that the $\mathrm{H}_{2}$ chemisorption gives the overall specific surface area, while the $\mathrm{CO}$ only the exposed surface area after $10 \mathrm{~min}$ of reaction. The sample Pd/N-CNT873K washed shows higher surface area in both cases than the Pd/N-CNT473K. Eventually, it is possible to calculate the TOF after $15 \mathrm{~min}$ of reaction normalised by the specific surface area at $10 \mathrm{~min}$ as $277 \mathrm{~mol} \mathrm{~m}^{-2} \mathrm{~h}^{-1}$ and $90 \mathrm{~mol} \mathrm{~m}{ }^{-2} \mathrm{~h}^{-1}$ for the $\mathrm{Pd} / \mathrm{N}-\mathrm{CNT} 873 \mathrm{~K}$ and the $\mathrm{Pd} / \mathrm{N}$ CNT473K, respectively. However, one must bear in mind that the value of the $\mathrm{CO}$ specific surface area changes with time. The observation shows that the as-prepared catalyst is a precatalyst packed into PVA. Only by chemisorption of the organic reactant the packaging is removed and activity begins. If the packaging with PVA is necessary to prevent sintering, it occurs that the reaction will change the morphological characteristic of the Pd. Strong metal-support interaction prevents this reaction-induced change. The dynamic rearrangement of sites arising from (a) freeing pre-covered $\mathrm{Pd}$, (b) restructuring due to sub-surface reaction and (c) sintering due to loss of metal-support interaction precludes a meaningful definition of a turnover frequency which is here a function of reaction time.

\section{Conclusion}

This work has shed light on the role of the PVA protective shell in the liquid phase oxidation reaction which is very often neglected in the literature. Obviously, the dissociative oxygen chemisorption on $\mathrm{Pd}$ is able to catalyse total oxidation reaction, which is indeed hindered by the specific adsorption geometry of oxygen on the Pd sites, constrained by the PVA and the benzyl alcohol chemisorbed on the catalyst surface. This is a general conclusion for these kinds of catalysts independently of the $\mathrm{C}$ surface properties.

The focus is placed on the understanding of the role that the surface chemistry of the carbon support plays in the catalytic performance of Pd-based catalyst in the selective oxidation of benzyl alcohol to benzaldehyde. Several observations and implications on the role of the surface chemistry of the support are pointed out as relevant for explaining the catalytic behaviour of these catalysts.

Due to the heterogeneity of the carbon surface, a certain degree of morphological and nano-structural heterogeneity was observed within the same sample and among the samples.

Among the samples, we have observed different activity and selectivity. In particular, the selectivity towards hydrogenolysis reaction is higher for less active catalysts. The TOF after $15 \mathrm{~min}$ of reaction normalised by the specific surface area is $277 \mathrm{~mol} \mathrm{~m}^{-2} \mathrm{~h}^{-1}$ and $90 \mathrm{~mol} \mathrm{~m}^{-2} \mathrm{~h}^{-1}$ for the Pd/N-CNT873K and the $\mathrm{Pd} / \mathrm{N}-\mathrm{CNT} 473 \mathrm{~K}$, respectively. Thus, the higher specific 
surface area and the adsorption geometry however cannot explain the enhanced catalytic activity of the Pd/N-CNT873K and the structure sensitivity of the reaction should be considered.

The Pd particles exhibit specific catalytic activities due to their morphologies. Besides adsorption, morphology also regulates sub-surface penetration of $\mathrm{O}, \mathrm{H}, \mathrm{C}$ from the reactants all modulating the electronic structure. As the morphology is in turn a function of the PVA coverage and metal-support interaction we observe a feed-back regulation of the performance. The support with its varying ability to strongly bind $\mathrm{Pd}$ modulates the feed-back mechanism. All this is superimposed in the time evolution of the activity shown in Fig. 1. The focus is placed on the specific basic functional group in the graphitic domains induced by the ammonia treatment at $673 \mathrm{~K}$ and $873 \mathrm{~K}$, which gives rise to stronger metal- $\mathrm{N}$ or metal-O bond at the interface which prevents them to undergo sintering during reaction. Those small particles are responsible for the enhanced catalytic performance.

\section{Acknowledgements}

The authors would like to thank Sylvia Reiche for supplying the $\mathrm{Pd}_{\mathrm{wi}} / \mathrm{CNT}$ reference sample and Prof. Manfred Baerns and Dr Axel Knop-Gericke for helpful discussion during the preparation of the manuscript.

\section{References}

1 J. S. Rafelt and J. H. Clark, Catal. Today, 2000, 57, 33-44.

2 J. H. J. Kluytmans, A. P. Markusse, M. B. F. Kuster, G. B. Marin and J. C. Schouten, Catal. Today, 2000, 57, 143-155.

3 V. R. Gangwal, J. van der Schaaf, B. F. M. Kuster and J. C. Schouten, J. Catal., 2005, 232, 432-443.

4 G. J. Hutchings, S. Carrettin, P. Landon, J. K. Edwards, D. Enache, D. W. Knight, Y.-J. Xu and A. F. Carley, Top. Catal., 2006, 38, 223-230.

5 R. A. Sheldon, I. W. C. E. Arends and A. Dijksman, Catal. Today, 2000, 57, 157-166.

6 N. Dimitratos, C. Messi, F. Porta, L. Prati and A. Villa, J. Mol. Catal. A: Chem., 2006, 256, 21-28.

7 S. Biella, F. Porta, L. Prati and M. Rossi, Catal. Lett., 2003, 90, 23-29.

8 F. Porta, L. Prati, M. Rossi, S. Coluccia and G. Martra, Catal. Today, 2000, 61, 165-172.

9 S. Derimel, K. Lehnert, M. Lucas and P. Claus, Appl. Catal., B, 2007, 70, 637-643.

10 G. J. ten Brink, I. W. C. E. Arends and R. A. Sheldon, Science, 2000, 287, 1636-1639.

11 Y. Li, E. Boone and M. A. El-Sayed, Langmuir, 2002, 18, 4921-4925.

12 R. G. DiScipio, Anal. Biochem., 1996, 236, 168-170.

13 X. Li, Y. Liu, L. Fu, L. Cao, D. Wei, G. Yu and D. Zhu, Carbon, 2006, 44, 3139.

14 A. Villa, D. Wang, P. Spontoni, R. Arrigo, D. S. Su and L. Prati, Catal. Today, 2010, 157, 89-93.

15 S. Abate, R. Arrigo, M. E. Schuster, S. Perathoner, G. Centi, A. Villa, D. Su and R. Schlögl, Catal. Today, 2010, 157, 280-285.

16 L. R. Radovic and F. Rodriguez-Reinoso, in Chemistry and Physics of Carbon, ed. P. A. Thrower, Marcel Dekker Inc., 1997, vol. 25.

17 K.-J. Kong, Y. Choi, B.-H. Ryu, J.-O. Lee and H. Chang, Mater. Sci. Eng., C, 2006, 26, 1207-1210.

18 B. Coq and F. Figueras, Coord. Chem. Rev., 1998, 178-180, $1753-1783$.

19 A. Y. Stakheev and L. M. Kustov, Appl. Catal., A, 1999, 188, 3-35.

20 B. H. Morrow and A. Striolo, Mol. Simul., 2009, 35, 795-803.
21 R. Arrigo, M. Hävecker, S. Wrabetz, R. Blume, M. Lerch, J. McGregor, E. P. J. Parrott, J. A. Zeitler, L. F. Gladden, A. Knop-Gericke, R. Schlögl and D. S. Su, J. Am. Chem. Soc., 2010, 132, 9616-9630.

22 A. Villa, N. Janjic, P. Spontoni, D. Wang, D. S. Su and L. Prati, Appl. Catal., A, 2009, 364, 221-228.

23 L. C. Josefowicz, H. G. Karge and E. N. Coker, J. Phys. Chem., 1994, 98, 8053.

24 A. Villa, D. Wang, N. Dimitratos, D. Su, V. Trevisan and L. Prati, Catal. Today, 2010, 150, 8-15.

25 K. Ohno and J. Tsuji, J. Am. Chem. Soc., 1968, 90, 99-107.

26 S. Mathew, C. Shiva Kumara and N. Nagaraju, J. Mol. Catal. A: Chem., 2006, 255, 243-248.

27 S. S. Hladyi, M. K. Starchevsky, Y. A. Pazdersky, M. N. Vargaftik and I. I. Moiseev, Mendeleev Commun., 2002, 12, 45-46.

28 C. Keresszegi, D. Ferri, T. Mallat and A. Baiker, J. Phys. Chem. B, 2005, 109, 958-967.

29 C. Keresszegi, T. Bürgi, T. Mallat and A. Baiker, J. Catal., 2002, 211, 244-251.

30 M. Ruta, N. Semagina and L. Kiwi-Minsker, J. Phys. Chem. C, 2008, 112, 13635-13641

31 B. Zhang, D. Wang, W. Zhang, D. S. Su and R. Schlögl, Chem. Eur. J., 2011, 17, 12877-12881.

32 U. Ulusoy and M. Yekeler, Int. J. Miner. Process., 2004, 74, 61-69.

33 D. Wang, A. Villa, F. Porta, L. Prati and D. Su, J. Phys. Chem. C, 2008, 112, 8617-8622.

34 C. R. Henry, C. Chapon, J. M. Penisson and G. Nihoul, Z. Phys. D: At., Mol. Clusters, 1989, 12, I45-148.

35 G. A. Somorjai and D. W. Blakely, Nature, 1975, 258, 580-583.

36 D. Teschner, A. Pestryakov, E. Kleimenov, M. Hävecker, H. Bluhm, H. Sauer, A. Knop-Gericke and R. Schlögl, J. Catal., 2005, 230, 195.

37 W. Vogel, J. Phys. Chem. C, 2011, 115, 1506-1512.

38 M. Maciejewski and A. Baker, Pure Appl. Chem., 1995, 67, $1879-1884$.

39 J. W. Jabobs and D. Schryvers, J. Catal., 1987, 103, 436-449.

40 R. M. Dell, D. F. Klemperer and F. S. Stone, J. Phys. Chem., 1956, 60, 1586-1588.

$41 \mathrm{M}$. Li and J. Shen, Thermochim. Acta, 2001, 379, 45-50.

42 Y.-S. Ho, C.-B. Wang and C.-T. Yeh, J. Mol. Catal. A: Chem., 1996, 112, 287-294.

43 S. Wrabetz, X. Yang, G. Tzolova-Müller, R. Schlögl and F. C. Jentoft, J. Catal., 2010, 269, 351-358.

44 G. Zheng and E. I. Altman, Surf. Sci., 2000, 462, 151-168.

45 J. Han, D. Y. Zemlyanov and F. H. Riberio, Surf. Sci., 2006, 600, $2730-2744$.

46 A. I. Titkov, A. N. Salanov, S. V. Koscheev and A. I. Boronin, Surf. Sci., 2006, 600, 4119-4125.

47 H. Gabasch, W. Unterberger, K. Hayek, B. Klötzer, E. Kleimenov, D. Teschner, S. Zafeiratos, M. Hävecker, A. Knop-Gericke, R. Schlögl, J. Han, F. H. Ribeiro, B. Aszalos-Kiss, T. Curtin and D. Zemlyanov, Surf. Sci., 2006, 600, 2980-2989.

48 D. Zemlyanov, B. Aszalos-Kiss, E. Kleimenov, D. Teschner, S. Zafeiratos, M. Hävecker, A. Knop-Gericke, R. Schlögl, H. Gabasch, W. Unterberger, K. Hayek and B. Klötzer, Surf. Sci., 2006, 600, 983-994.

49 T. Schalow, B. Brandt, D. E. Starr, M. Laurin, S. Schauermann, Sh. K. Shaikhutdinov, J. Libuda and H.-J. Freund, Catal. Lett., 2006, 107.

50 G. Ketteler, D. F. Ogletree, H. Bluhm, H. Liu, E. L. D. Hebenstreit and M. Salmeron, J. Am. Chem. Soc., 2005, 127, 18269-18273.

51 J. E. Turner and M. B. Maple, Surf. Sci., 1984, 147, 647-662.

52 G. D. Zakumbaeva and S. V. Artamonov, React. Kinet. Catal. Lett., 1979, 10, 183-186.

53 J. M. Guil, J. E. Herrero Garcia, A. Ruiz Paniego and J. M. Trejo Menayo, Top. Catal., 2002, 19, 313.

$54 \mathrm{Yu}$. K. Tovbin and O. V. Kuznetsova, Institute of Physical Chemistry, Academy of Sciences of the USSR, Moscow. Translated from Izvestiya Akademii Nauk SSSR, Seriya Khimicheskaya, No. 11, pp. 2619-2622, November, 1990. Original article submitted December 19, 1989 . 